\title{
Optimization of Case Treatment AISI 1022 Timber Screw Process Parameters Using Taguchi Method
}

\author{
Chih-Cheng Yang* and Ching-Yun Yen \\ Department of Mechanical Engineering and Automation Engineering, Kao Yuan University, \\ Kaohsiung 821, Taiwan, R.O.C.
}

(Received July 3, 2017; accepted November 2, 2017)

Keywords: timber screw, case treatment, Taguchi method, case hardness, torsional strength

The manufacturing processes of timber screws, which are widely used for wood construction work, include wire manufacturing, heading and threading, case treatment, and coating. A lowcarbon steel wire of AISI 1022 is used to easily fabricate timber screws. The majority of case treatment activities are performed to improve the screw strength without affecting the soft, tough interior of the screws in drilling operation. In this study, the Taguchi method is used to obtain optimum case treatment conditions to improve the mechanical properties of AISI 1022 timber screws. The quality of case-treated timber screws is affected by various factors, such as case treatment temperature, case treatment time, atmosphere composition, and tempering temperature. The effects of case treatment parameters affect the quality characteristics, such as case hardness and torsional strength. It is experimentally revealed that ammonia flow rate, case treatment time, and carbon potential are significant for case hardness, while methanol flow rate, case treatment temperature, and case treatment time are significant for torsional strength. The optimum mean case hardness is $673.1 \mathrm{HV}$, the optimum mean core hardness is $440.0 \mathrm{HV}$ and, for torsional strength, the optimum mean value is $5.3 \mathrm{~N} \cdot \mathrm{m}$. The new case treatment parameter settings evidently improve the performance. The strength of the case-treated AISI 1022 timber screws is effectively improved. These results may be used as a reference for fastener manufacturers.

\section{Introduction}

The manufacturing processes of timber screws, which are widely used for construction work, include wire manufacturing, forming, heat treatment, and coating. To readily fabricate timber screws, low-carbon steel wires are usually used. To increase the strength of screws in self-drilling operation, case hardening treatment is usually an essential process that is used to improve the wear resistance and not affect the soft, tough interior of the screws. This combination of a hard surface and resistance to breakage is valuable in the manufacture of timber screws, which have a hard surface to resist wear, along with a tough interior to resist the breakage that occurs during self-drilling operation.

*Corresponding author: e-mail: t30043@cc.kyu.edu.tw http://dx.doi.org/10.18494/SAM.2018.1749 
Gas carburization is a case hardening process in which carbon is dissolved in the surface layers of a low-carbon steel part at a temperature sufficient to make the steel austenitic, followed by quenching and tempering to form a martensitic microstructure. ${ }^{(1)}$ Various principal variables, such as temperature, time, and atmosphere composition, affect the quality of gas carburization. Goldstein and $\operatorname{Moren}^{(2)}$ had developed mathematical models for simulating the carburization process. One model simulates carburization in low-alloy steels by varying the temperature, time, surface carbon content, and diffusion coefficient during the process. Experimental data for carburization treatments of $\mathrm{Fe}-\mathrm{C}-\mathrm{Cr}$ alloys were in excellent agreement with model predictions of major increases in effective surface carbon content and the formation of carbides in austenite at the carburization temperature.

The carburization temperature varies from 870 to $940{ }^{\circ} \mathrm{C}$ and the gas atmosphere for carburization is produced from a liquid or gaseous hydrocarbon such as propane, butane or methane. $^{(3)}$ The process converts the outer layer of a screw into a high-carbon steel with a carbon content in the range of $0.9-1.2 \%$. Effective case depth is an important factor and goal in gas carburization, involving complicated procedures in the furnace and requiring precise control of many thermal parameters. ${ }^{(4)}$ The effective case depth governed by carburization temperature, time, the carbon content of steel, and the carbon potential of atmosphere is calculated, and a simple and practical set of guidelines for optimizing gas carburization has been provided for plant production. Aramide et al. ${ }^{(5)}$ studied the effects of the carburization temperature and time on the mechanical properties of mild steels carburized with activated carbon, and observed that the mechanical properties of mild steels were strongly affected by the process of carburization, carburization temperature, and soaking time at the carburization temperature. They concluded that the optimum combination of mechanical properties is achieved at the carburization temperature of $900{ }^{\circ} \mathrm{C}$ followed by oil quenching and tempering at $550{ }^{\circ} \mathrm{C}$. Peng et al ${ }^{(6)}$ studied the carburizing behaviors and mechanisms of $\mathrm{Cr} 35 \mathrm{Ni} 45 \mathrm{Nb}$ alloy subjected to different service conditions in a high-temperature vacuum environment. Ivanov et al. ${ }^{(7)}$ studied carburization and different heat treatments of low-carbon martensitic steel 24Kh2G2NMFB and suggested heat treatment modes to improve the structure of the surface layer after carburization.

Carbonitridation, a modified form of gas carburization, induced by diffusing both carbon and nitrogen into the surface layer enables the process to be carried out at a lower temperature and a shorter time than with carbon alone. Carbonitridation is used primarily to impart a hard, wear-resistant case. The case depth depends on the time and temperature of treatment. Carbonitridation is an excellent choice for low-carbon fastener materials that require a uniform but shallow case with good wear properties. ${ }^{(8)}$ Besides the process temperature, the combined diffusion profile of carbon and nitrogen applied in carbonitridation plays a major role. Winter ${ }^{(9)}$ presented a new system that enables us to measure and control both the carbon potential and the nitrogen potential independently. Slycke and Ericsson ${ }^{(10)}$ have studied theoretically and experimentally the reactions occurring during carbonitridation. Semenova et al. ${ }^{(11)}$ considered the regular features of the formed diffusion layers in the temperature-cycle carbonitridation of steel $20 \mathrm{Kh}$ and used the solution of the general diffusion problem to determine the diffusivity of carbon. Karamiş and İpek ${ }^{(12)}$ investigated the wear behavior of carburized and carbonitrided AISI 1020 and 5115 steels. The carbonitrided 5115 steel has the highest wear resistance 
followed by the carburized 5115, carbonitrided 1020, and carburized 1020 steels. Fares et al. ${ }^{(13)}$ investigated gaseous carbonitriding effects on the improvement of the surface characteristics of a new hot working tool steel close to either chromium AISI H11 or AISI H13. The microstructure and diffusion mechanism suggested that high-temperature gas carbonitridation has the potential to improve the mechanical properties of steels with shorter processing time.

In this study, in order to obtain the optimum case treatment quality of AISI 1022 timber screws, a series of case treatment experiments is conducted in a continuous furnace. Various parameters, such as quenching temperature, case treatment time, atmosphere composition (carbon potential and ammonia level), and tempering temperature, affect the case treatment quality. The effects of treatment parameters on the quality characteristics of timber screws, such as case hardness, core hardness, and torsional strength, are analyzed by using the Taguchi method.

\section{Experimental Design}

Carburization and Carbonitridation are often used to achieve deeper case depths and higher engineering performance for timber screws. A series of case treatment experiments on AISI 1022 timber screws is conducted in a continuous furnace and then the screws are oil-quenched and tempered at $230{ }^{\circ} \mathrm{C}$ for $45 \mathrm{~min}$.

To evaluate the mechanical properties of the timber screws, seven controllable process factors are identified: 1 at two levels and 6 at three levels. All factors and their levels are shown in Table 1. The parameters of Level 2 are the original case treatment conditions, which were used in the company.

The Taguchi method allows simultaneous changes of many factors in a systematic manner, ensuring the reliable and independent study of the factors' effects. The orthogonal array table, $\mathrm{L}_{18}\left(2^{1} \times 3^{7}\right),{ }^{(14,15)}$ is used as an experimental design for these seven factors, as shown in Table 2 .

In this study, two quality characteristics of the case-treated timber screws, namely, case hardness (as measured in Fig. 1) and torsional strength, are investigated. Each test trial, including nine specimens, is followed by a fabrication process and the results are then transformed to the signal-to-noise $(\mathrm{S} / \mathrm{N})$ ratio. For a nontreated screw, the case hardness of 208.3 HV is measured on the tooth and the core hardness of $173.0 \mathrm{HV}$ is tested at the center of the screw, as shown in Fig. 1. Since the hardness of the workpiece may be increased by plastic

Table 1

Experimental factors and their levels for $\mathrm{L}_{18}$ orthogonal array.

\begin{tabular}{llccc}
\hline & Factor & Level 1 & Level 2 & Level 3 \\
\hline A: & Flow rate of ammonia $\left(\mathrm{NH}_{3}\right)(\mathrm{L} / \mathrm{min})$ & 0.5 & $0.0^{*}$ & \\
B: & Flow rate of methanol $\left(\mathrm{CH}_{3} \mathrm{OH}\right)(\mathrm{L} / \mathrm{min})$ & 1.0 & 1.5 & 2.0 \\
$\mathrm{C}:$ & Feeding weight $(\mathrm{kg} / \mathrm{h})$ & 600 & 700 & 800 \\
D: & Case treating temperature $\left({ }^{\circ} \mathrm{C}\right)$ & 860 & 880 & 900 \\
E: & Case treating time $(\min )$ & 40 & 50 & 60 \\
F: & Carbon potential $(\%)$ & 0.9 & 1.0 & 1.1 \\
G: & Quenchant temperature $\left({ }^{\circ} \mathrm{C}\right)$ & 80 & 85 & 90 \\
\hline
\end{tabular}

${ }^{*}$ Without ammonia $(0.0 \mathrm{~L} / \mathrm{min})$ for carburization. 
Table 2

$\mathrm{L}_{18}\left(2^{1} \times 3^{7}\right)$ orthogonal array experimental parameter assignment.

\begin{tabular}{lccccccc}
\hline Exp. & $\begin{array}{c}\text { A: } \\
\text { Flow rate } \\
\text { of ammonia } \\
\left(\mathrm{NH}_{3}\right) \\
(\mathrm{L} / \mathrm{min})\end{array}$ & $\begin{array}{c}\text { B: } \\
\text { Flow rate of } \\
\text { methanol } \\
\left(\mathrm{CH}_{3} \mathrm{OH}\right) \\
(\mathrm{L} / \mathrm{min})\end{array}$ & $\begin{array}{c}\mathrm{C} \text { : } \\
\text { Feeding } \\
\text { weight } \\
(\mathrm{kg} / \mathrm{h})\end{array}$ & $\begin{array}{c}\mathrm{D} \text { : } \\
\text { Case treating } \\
\text { temperature } \\
\left({ }^{\circ} \mathrm{C}\right)\end{array}$ & $\begin{array}{c}\text { E: } \\
\text { Case treating } \\
\text { time } \\
(\mathrm{min})\end{array}$ & $\begin{array}{c}\text { F: } \\
\text { Carbon } \\
\text { potential } \\
(\%)\end{array}$ & $\begin{array}{c}\text { G: } \\
\text { Quenchant } \\
\text { temperature } \\
\left({ }^{\circ} \mathrm{C}\right)\end{array}$ \\
\hline L1 & 0.5 & 1.0 & 600 & 860 & 40 & 0.9 & 80 \\
L2 & 0.5 & 1.0 & 700 & 880 & 50 & 1.0 & 85 \\
L3 & 0.5 & 1.0 & 800 & 900 & 60 & 1.1 & 90 \\
L4 & 0.5 & 1.5 & 600 & 860 & 50 & 1.0 & 90 \\
L5 & 0.5 & 1.5 & 700 & 880 & 60 & 1.1 & 80 \\
L6 & 0.5 & 1.5 & 800 & 900 & 40 & 0.9 & 85 \\
L7 & 0.5 & 2.0 & 600 & 880 & 40 & 1.1 & 85 \\
L8 & 0.5 & 2.0 & 700 & 900 & 50 & 0.9 & 90 \\
L9 & 0.5 & 2.0 & 800 & 860 & 60 & 1.0 & 80 \\
L10 & 0.0 & 1.0 & 600 & 900 & 60 & 1.0 & 85 \\
L11 & 0.0 & 1.0 & 700 & 860 & 40 & 1.1 & 90 \\
L12 & 0.0 & 1.0 & 800 & 880 & 50 & 0.9 & 80 \\
L13 & 0.0 & 1.5 & 600 & 880 & 60 & 0.9 & 90 \\
L14 & 0.0 & 1.5 & 700 & 900 & 40 & 1.0 & 80 \\
L15 & 0.0 & 1.5 & 800 & 860 & 50 & 1.1 & 85 \\
L16 & 0.0 & 2.0 & 600 & 900 & 50 & 1.1 & 80 \\
L17 & 0.0 & 2.0 & 700 & 860 & 60 & 0.9 & 85 \\
L18 & 0.0 & 2.0 & 800 & 880 & 40 & 1.0 & 90 \\
\hline
\end{tabular}

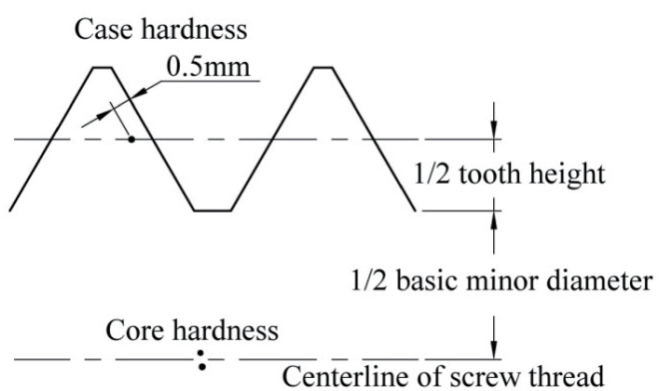

Fig. 1. Schematic illustration of measuring case hardness and core hardness.

flow, ${ }^{(16)}$ the case hardness is greater than the core hardness mainly owing to the plastic work of threading. The torsional strength is only $2.83 \mathrm{~N} \cdot \mathrm{m}$.

Through case treatment, the strength of timber screws may be improved, and the case hardness, which is the main quality characteristic obtained from the Vickers hardness test, and torsional strength (drilling performance) may be increased as well. Both quality characteristics are with nominal values of $600 \mathrm{HV}$ case hardness and $4.5 \mathrm{~N} \cdot \mathrm{m}$ torsional strength, assigned by the company. Therefore, in terms of the desired characteristics for the case hardness and torsional strength, the $\mathrm{S} / \mathrm{N}$ ratio for the nominal-the-best response is ${ }^{(15)}$

$$
S / N=-10 \cdot \log \left[(\mu-m)^{2}+S^{2}\right],
$$


where $\mu$ is the mean of each trial, $m$ is the target value, and $S$ is the standard deviation.

The analysis of variance (ANOVA) is an effective method of determining the significant factors and optimal fabrication conditions to obtain the optimal quality. In the Taguchi method, the experimental error is evaluated by ANOVA to carry out the significance test of the various factors. The nature of the interaction between factors is considered as experimental error. $^{(15)}$ If the effect of a factor in comparison with the experimental error is sufficiently large, it is identified as a significant factor. The confidence level of a factor is evaluated with the experimental error to identify the significant factor that affects the material properties of the timber screws.

\section{Materials and Methods}

In this study, the AISI 1022 steel wire coil is manufactured by TYCOONS Worldwide Group (Thailand) Public Co., Ltd. Its chemical composition is shown in Table 3. A series of case treatment experiments on AISI 1022 timber screws $(\# 8 \times 2-1 / 2$ CS) is conducted in a CCF-CF-7-E continuous furnace (Chuang Young Enterprise Co., Ltd., Yunlin, Taiwan), and then the screws are oil-quenched and tempered at $230{ }^{\circ} \mathrm{C}$ for $45 \mathrm{~min}$. The case treatment procedure is shown in Fig. 2. The Taguchi method allows simultaneous changes of many factors in a systematic manner. The orthogonal array table, $\mathrm{L}_{18}\left(2^{1} \times 3^{7}\right)$, is used as an experimental design for the factors, ${ }^{(15)}$ as shown in Table 2.

\section{Results and Discussion}

Case treatment is the process of diffusing carbon and/or nitrogen into the surface layer, as shown in Fig. 3, to impart a hard, wear-resistant case. Compared with the measures of nontreated screws, the core hardness and case hardness increase together, although the

Table 3

Chemical composition of AISI 1022 low-carbon steel wires (wt\%).

\begin{tabular}{cccccc}
\hline $\mathrm{C}$ & $\mathrm{Mn}$ & $\mathrm{P}$ & $\mathrm{S}$ & $\mathrm{Si}$ & $\mathrm{Al}$ \\
\hline $0.18-0.23$ & $0.74-0.84$ & $0.009-0.025$ & $0.007-0.014$ & $0.04-0.06$ & $0.028-0.053$ \\
\hline
\end{tabular}

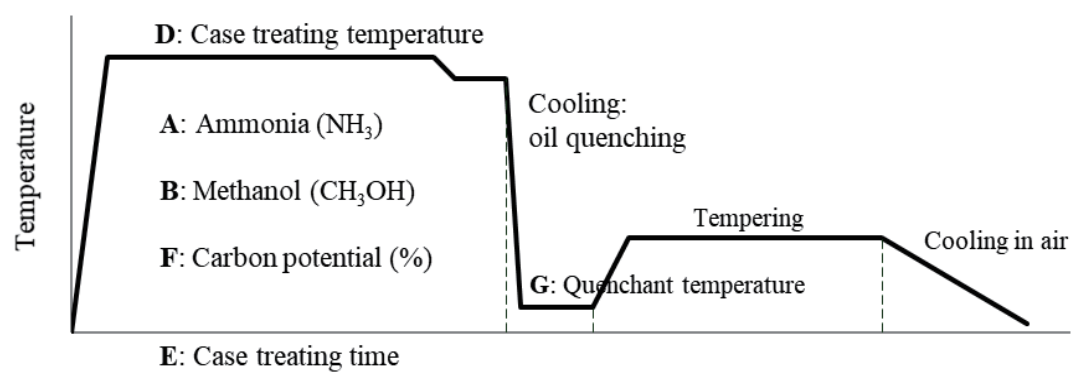

Fig. 2. Case treating procedure. 


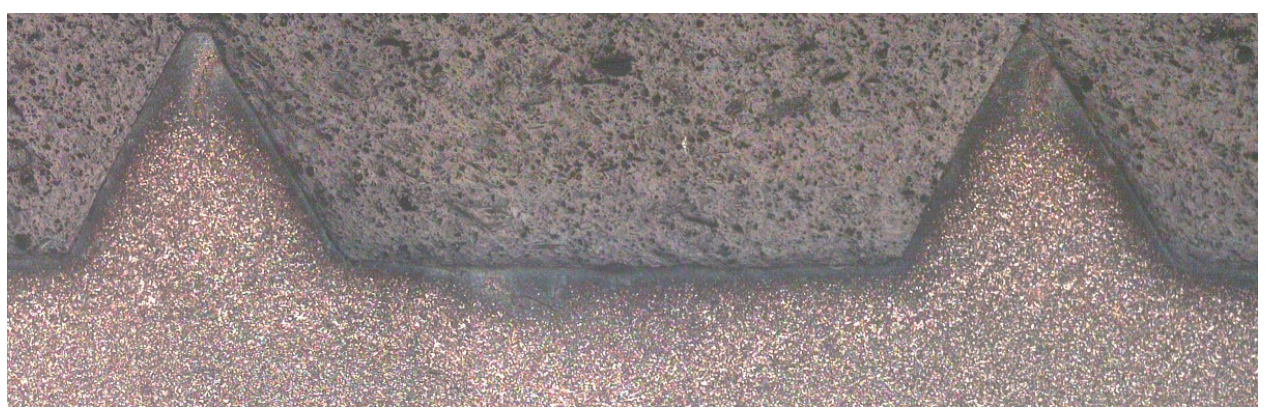

Fig. 3. (Color online) Microstructure of timber screw $(\times 200)$.

increment of case hardness (more than $450 \mathrm{HV}$ ) is much higher than that of core hardness (less than $300 \mathrm{HV}$ ); the torsional strength also increases.

When the screws are fabricated following the original case treatment conditions (Level 2 in Table 1), the mean torsional strength, case hardness, and core hardness are $6.56 \mathrm{~N} \cdot \mathrm{m}, 660.3 \mathrm{HV}$, and $460.6 \mathrm{HV}$, respectively. The experimental results of the torsional strength, case hardness, and core hardness (mean, $\mu$; standard deviation, $S$; and $\mathrm{S} / \mathrm{N}$ ratio) of case-treated timber screws are respectively shown in Tables 4, 5, and 6.

As shown in Table 4, the mean torsional strengths of all tests are larger than the target value of 4.5 $\mathrm{N} \cdot \mathrm{m}$. The standard deviation varies from 0.082 to $0.188 \mathrm{~N} \cdot \mathrm{m}$ and tests L5, L6, and L7 are the smallest among the eighteen tests. The mean case hardness varies from 634.0 to $730.2 \mathrm{HV}$, and the mean values of all tests exceed $600 \mathrm{HV}$, as shown in Table 5. The standard deviation varies from 10.97 to $34.61 \mathrm{HV}$ and test L16 is the smallest among the eighteen tests. As shown in Table 6, the mean core hardness varies from 427.3 to $448.7 \mathrm{HV}$ and the mean values are smaller than the value at the original settings. The standard deviation varies from 4.90 to $15.86 \mathrm{HV}$ and test L5 is the smallest among the eighteen tests. The properties of case-treated timber screws are clearly altered under various case treatment conditions.

\subsection{Case hardness}

To obtain the optimum quality, ANOVA is performed to determine significant factors and optimum fabrication conditions. The contribution and confidence level of each factor shown in Table 7 could identify the significant factor affecting the case hardness of case-treated timber screws. The contribution of a factor is the percentage of the sum of squares $(S S)$, that is, the percentage of the factor variance to the total quality loss. ${ }^{(14,15)}$ The effect of a factor may be pooled to error if its confidence level or contribution is relatively small. It is obvious from the ANOVA table that the contribution of ammonia flow rate (A) is $52.7 \%$ of the total variation, which is the highest contributor to the variability of the experimental results. The contributions of carbon potential (F) and case treatment time (E) are 12.1 and $11.5 \%$, which are the second and third highest contributions, respectively. However, the other four factors are not significant for the $\mathrm{S} / \mathrm{N}$ ratio since their contributions are relatively small. By pooling the errors from the nonsignificant factors (B, C, D, and G), the error for the $\mathrm{S} / \mathrm{N}$ ratio is estimated ${ }^{(15)}$ and then the 
Table 4

Experimental results for torsional strength.

\begin{tabular}{|c|c|c|c|c|c|c|c|c|c|c|c|c|}
\hline $\begin{array}{l}\text { Exp. } \\
\text { No.* }\end{array}$ & $\mathrm{T} 1$ & $\mathrm{~T} 2$ & T3 & $\mathrm{T} 4$ & T5 & T6 & $\mathrm{T} 7$ & $\mathrm{~T} 8$ & T9 & $\mu(\mathrm{N} \cdot \mathrm{m})$ & $S$ & $\begin{array}{l}\mathrm{S} / \mathrm{N} \\
\text { ratio }\end{array}$ \\
\hline L1 & 6.28 & 6.28 & 6.08 & 6.28 & 6.08 & 6.28 & 6.28 & 6.28 & 6.47 & 6.26 & 0.111 & -4.91 \\
\hline L2 & 6.67 & 6.47 & 6.67 & 6.47 & 6.28 & 6.47 & 6.47 & 6.67 & 6.47 & 6.52 & 0.123 & -6.12 \\
\hline L3 & 6.67 & 6.67 & 6.67 & 6.47 & 6.47 & 6.67 & 6.47 & 6.67 & 6.47 & 6.58 & 0.097 & -6.39 \\
\hline L4 & 6.28 & 6.67 & 6.67 & 6.47 & 6.47 & 6.67 & 6.67 & 6.67 & 6.47 & 6.56 & 0.134 & -6.30 \\
\hline L5 & 6.47 & 6.47 & 6.47 & 6.47 & 6.47 & 6.47 & 6.67 & 6.67 & 6.47 & 6.52 & 0.082 & -6.11 \\
\hline L6 & 6.47 & 6.67 & 6.67 & 6.67 & 6.47 & 6.67 & 6.67 & 6.67 & 6.67 & 6.63 & 0.082 & -6.56 \\
\hline L7 & 6.47 & 6.47 & 6.47 & 6.47 & 6.47 & 6.67 & 6.67 & 6.47 & 6.47 & 6.52 & 0.082 & -6.11 \\
\hline L8 & 6.67 & 6.67 & 6.28 & 6.67 & 6.47 & 6.67 & 6.67 & 6.47 & 6.47 & 6.56 & 0.134 & -6.30 \\
\hline L9 & 6.28 & 6.67 & 6.67 & 6.28 & 6.87 & 6.47 & 6.67 & 6.47 & 6.47 & 6.54 & 0.185 & -6.23 \\
\hline L10 & 6.28 & 6.67 & 6.47 & 6.47 & 6.28 & 6.67 & 6.47 & 6.47 & 6.47 & 6.47 & 0.131 & -5.93 \\
\hline L11 & 6.08 & 6.28 & 6.28 & 6.47 & 6.47 & 6.28 & 6.28 & 6.28 & 6.28 & 6.30 & 0.111 & -5.12 \\
\hline L12 & 6.67 & 6.87 & 6.87 & 6.87 & 6.67 & 6.67 & 6.47 & 6.67 & 6.67 & 6.71 & 0.123 & -6.92 \\
\hline L13 & 6.47 & 6.67 & 6.87 & 6.67 & 6.47 & 6.87 & 6.67 & 6.47 & 6.67 & 6.65 & 0.145 & -6.66 \\
\hline L14 & 6.47 & 6.67 & 6.67 & 6.67 & 6.67 & 6.47 & 6.67 & 6.47 & 6.87 & 6.63 & 0.123 & -6.57 \\
\hline L15 & 6.28 & 6.47 & 6.47 & 6.47 & 6.67 & 6.47 & 6.87 & 6.87 & 6.47 & 6.56 & 0.188 & -6.32 \\
\hline L16 & 6.67 & 6.87 & 7.06 & 7.06 & 7.06 & 6.87 & 6.87 & 6.87 & 6.87 & 6.91 & 0.123 & -7.65 \\
\hline L17 & 6.47 & 6.67 & 6.87 & 6.67 & 6.47 & 6.67 & 6.67 & 6.47 & 6.67 & 6.63 & 0.123 & -6.57 \\
\hline L18 & 6.67 & 6.47 & 6.47 & 6.47 & 6.47 & 6.67 & 6.28 & 6.47 & 6.28 & 6.47 & 0.131 & -5.93 \\
\hline
\end{tabular}

*Experimental conditions as defined in Table 2.

Table 5

Experimental results for case hardness.

\begin{tabular}{lcccccccccccc}
\hline $\begin{array}{l}\text { Exp. } \\
\text { No. }\end{array}$ & T1 & T2 & T3 & T4 & T5 & T6 & T7 & T8 & T9 & $\mu(H V)$ & $S$ & $\begin{array}{c}\text { S/N } \\
\text { ratio }\end{array}$ \\
\hline L1 & 697 & 663 & 698 & 691 & 601 & 681 & 698 & 684 & 616 & 669.9 & 34.61 & -37.8 \\
L2 & 716 & 692 & 735 & 731 & 726 & 730 & 720 & 692 & 728 & 718.9 & 15.34 & -41.6 \\
L3 & 659 & 730 & 713 & 702 & 682 & 656 & 735 & 648 & 693 & 690.9 & 30.27 & -39.6 \\
L4 & 690 & 686 & 723 & 699 & 706 & 720 & 701 & 666 & 696 & 698.6 & 16.39 & -40.0 \\
L5 & 770 & 749 & 706 & 729 & 720 & 766 & 724 & 704 & 704 & 730.2 & 24.32 & -42.4 \\
L6 & 697 & 716 & 692 & 674 & 692 & 697 & 664 & 714 & 684 & 692.2 & 15.92 & -39.4 \\
L7 & 711 & 747 & 691 & 689 & 694 & 646 & 706 & 684 & 710 & 697.6 & 25.43 & -40.1 \\
L8 & 659 & 678 & 681 & 646 & 699 & 687 & 746 & 709 & 667 & 685.8 & 28.04 & -39.1 \\
L9 & 681 & 664 & 707 & 618 & 626 & 691 & 706 & 638 & 641 & 663.6 & 32.31 & -37.1 \\
L10 & 653 & 642 & 634 & 612 & 641 & 656 & 603 & 656 & 609 & 634.0 & 19.75 & -31.9 \\
L11 & 651 & 712 & 680 & 671 & 693 & 729 & 687 & 632 & 665 & 680.0 & 28.08 & -38.6 \\
L12 & 656 & 685 & 664 & 661 & 697 & 668 & 679 & 676 & 669 & 672.8 & 12.11 & -37.4 \\
L13 & 614 & 671 & 652 & 615 & 656 & 623 & 630 & 663 & 670 & 643.8 & 21.99 & -33.8 \\
L14 & 683 & 693 & 700 & 641 & 663 & 693 & 657 & 654 & 673 & 673.0 & 19.35 & -37.6 \\
L15 & 661 & 680 & 679 & 652 & 655 & 656 & 657 & 640 & 643 & 658.1 & 13.05 & -35.5 \\
L16 & 663 & 696 & 682 & 679 & 680 & 658 & 674 & 682 & 687 & 677.9 & 10.97 & -37.9 \\
L17 & 647 & 643 & 678 & 641 & 604 & 621 & 649 & 652 & 646 & 642.3 & 19.36 & -33.4 \\
L18 & 650 & 648 & 691 & 647 & 643 & 654 & 654 & 663 & 627 & 653.0 & 16.30 & -34.9 \\
\hline
\end{tabular}

*Experimental conditions as defined in Table 2. 
Table 6

Experimental results for core hardness.

\begin{tabular}{|c|c|c|c|c|c|c|c|c|c|c|c|}
\hline $\begin{array}{l}\text { Exp. } \\
\text { No. }\end{array}$ & $\mathrm{T} 1$ & $\mathrm{~T} 2$ & $\mathrm{~T} 3$ & $\mathrm{~T} 4$ & T5 & T6 & $\mathrm{T} 7$ & $\mathrm{~T} 8$ & T9 & $\mu(\mathrm{HV})$ & $S$ \\
\hline L1 & 431 & 446 & 436 & 434 & 449 & 466 & 461 & 421 & 423 & 440.8 & 15.86 \\
\hline L2 & 453 & 444 & 431 & 443 & 437 & 432 & 453 & 437 & 446 & 441.8 & 8.17 \\
\hline L3 & 441 & 420 & 427 & 424 & 443 & 435 & 433 & 433 & 436 & 432.4 & 7.58 \\
\hline L4 & 437 & 432 & 442 & 437 & 434 & 442 & 447 & 431 & 441 & 438.1 & 5.30 \\
\hline L5 & 433 & 437 & 443 & 446 & 432 & 436 & 437 & 444 & 440 & 438.7 & 4.90 \\
\hline L6 & 428 & 456 & 434 & 434 & 428 & 440 & 433 & 432 & 438 & 435.9 & 8.52 \\
\hline L7 & 450 & 456 & 461 & 454 & 446 & 447 & 431 & 439 & 454 & 448.7 & 9.22 \\
\hline L8 & 447 & 443 & 440 & 444 & 455 & 452 & 439 & 431 & 440 & 443.4 & 7.23 \\
\hline L9 & 462 & 434 & 441 & 454 & 432 & 438 & 454 & 444 & 459 & 446.4 & 11.09 \\
\hline L10 & 437 & 444 & 450 & 453 & 425 & 431 & 442 & 425 & 426 & 437.0 & 10.86 \\
\hline L11 & 436 & 451 & 421 & 437 & 452 & 433 & 437 & 439 & 450 & 439.6 & 10.05 \\
\hline L12 & 428 & 426 & 446 & 432 & 441 & 431 & 436 & 417 & 453 & 434.4 & 10.94 \\
\hline L13 & 440 & 419 & 418 & 425 & 413 & 445 & 438 & 412 & 436 & 427.3 & 12.57 \\
\hline L14 & 442 & 415 & 454 & 449 & 413 & 419 & 431 & 437 & 449 & 434.3 & 15.64 \\
\hline L15 & 450 & 438 & 454 & 448 & 434 & 451 & 461 & 454 & 437 & 447.4 & 9.14 \\
\hline L16 & 436 & 440 & 435 & 448 & 446 & 461 & 449 & 451 & 445 & 445.7 & 8.06 \\
\hline L17 & 452 & 451 & 441 & 444 & 452 & 429 & 411 & 433 & 448 & 440.1 & 13.70 \\
\hline L18 & 429 & 431 & 430 & 433 & 436 & 437 & 443 & 443 & 423 & 433.9 & 6.58 \\
\hline
\end{tabular}

*Experimental conditions as defined in Table 2.

Table 7

ANOVA results of $\mathrm{S} / \mathrm{N}$ ratio for case hardness.

\begin{tabular}{lrccc}
\hline Factor & \multicolumn{1}{c}{$S S$} & DOF & Var. & Contribution (\%) \\
\hline $\mathrm{A}$ & 73.25 & 1 & 73.25 & 52.71 \\
$\mathrm{~B}$ & 3.53 & 2 & 1.76 & 2.54 \\
$\mathrm{C}$ & 11.41 & 2 & 5.71 & 8.21 \\
$\mathrm{D}$ & 5.14 & 2 & 2.57 & 3.70 \\
$\mathrm{E}$ & 16.04 & 2 & 8.02 & 11.54 \\
$\mathrm{~F}$ & 16.88 & 2 & 8.44 & 12.15 \\
G & 5.82 & 2 & 2.91 & 4.19 \\
Others & 6.90 & 4 & 1.72 & 4.96 \\
Total & 138.96 & 17 & - & 100.00 \\
\hline Pooling & & & &
\end{tabular}

\begin{tabular}{|c|c|c|c|c|c|c|}
\hline \multicolumn{7}{|c|}{ Pooling of errors } \\
\hline Factor & $S S$ & DOF & Var. & $F$ & Confidence (\%) & Significance \\
\hline A & 73.25 & 1 & 73.25 & 26.80 & 99.98 & Yes \\
\hline B & \multicolumn{6}{|c|}{ Pooled } \\
\hline $\mathrm{C}$ & \multicolumn{6}{|c|}{ Pooled } \\
\hline $\mathrm{D}$ & \multicolumn{6}{|c|}{ Pooled } \\
\hline $\mathrm{E}$ & 16.04 & 2 & 8.02 & 2.93 & 90.83 & Yes \\
\hline $\mathrm{F}$ & 16.88 & 2 & 8.44 & 3.09 & 91.72 & Yes \\
\hline G & \multicolumn{6}{|c|}{ Pooled } \\
\hline Others & \multicolumn{6}{|c|}{ Pooled } \\
\hline Error & 32.80 & 12 & 2.73 & & & \\
\hline Total & 138.96 & 17 & \multicolumn{4}{|c|}{${ }^{*}$ At least $90.00 \%$ confidence level } \\
\hline
\end{tabular}

$S S$, sum of squares; DOF, degree of freedom; Var., variance; $F, F$-ratio; $S_{\text {exp }}$, experimental error 
confidence levels are determined to be 100.0, 90.8, and 91.7\% for ammonia flow rate (A), case treatment time (E), and carbon potential (F), respectively. That is, the three factors significantly affect the case hardness of case-treated timber screws with a confidence level of more than $90.0 \%$.

Figure 4 illustrates the factor response diagram and the level averages of seven factors with respect to the $\mathrm{S} / \mathrm{N}$ ratio. For each factor, the effect is the range of level averages and the maximum level average is the optimum level. ${ }^{(14,15)}$ It is clearly revealed that, for the significant factors of ammonia flow rate (A), case treatment time (E), and carbon potential (F), Level 2 for ammonia flow rate $(0.0 \mathrm{~L} / \mathrm{min}, \mathrm{A} 2)$, Level 3 for case treatment time $(60 \mathrm{~min}, \mathrm{E} 3)$ and Level 1 for carbon potential $(0.9 \%, \mathrm{~F} 1)$ are evidently optimum, as shown in Fig. 4 . The effects of the other four factors are relatively small. The optimum levels are Level 3 for methanol flow rate (2.0 $\mathrm{L} / \mathrm{min}, \mathrm{B} 3)$, Level 1 for feeding weight $(600 \mathrm{~kg} / \mathrm{h}, \mathrm{C} 1)$, Level 1 for case treatment temperature (860 ${ }^{\circ} \mathrm{C}$, D1), and Level 2 for quenchant temperature $\left(85^{\circ} \mathrm{C}\right.$, G2).

\subsection{Torsional strength}

For the torsional strength of case-treated timber screws, the ANOVA results of $\mathrm{S} / \mathrm{N}$ ratio are shown in Table 8. It is evident from Table 8 that the highest contributor to the variability of the experimental results is the case treatment time (E), whose contribution reaches $26.4 \%$. The contributions of case treatment temperature (D) and methanol flow rate (B) are 21.1 and $19.2 \%$, which are the second and third highest contributions, respectively. The other factors are not significant because their contributions are relatively small. By pooling the errors from the nonsignificant factors (A, C, F, and G), the error for the $\mathrm{S} / \mathrm{N}$ ratio is estimated ${ }^{(15)}$ and then the confidence levels are determined to be $91.8,93.2$, and $95.9 \%$ for methanol flow rate (B), case treatment temperature (D) and case treatment time (E), respectively. That is, the three factors significantly affect the torsional strength of case-treated timber screws, with a confidence level of more than $90.0 \%$.

The factor response diagram and the level averages of seven factors with respect to the $\mathrm{S} / \mathrm{N}$ ratio are illustrated in Fig. 5. It is clearly revealed that, for the significant factors of methanol flow rate (B), case treatment temperature (D), and case treatment time (E), Level 1 for methanol flow rate $(1.0 \mathrm{~L} / \mathrm{min}, \mathrm{B} 1)$, Level 1 for case treatment temperature $\left(860^{\circ} \mathrm{C}, \mathrm{D} 1\right)$, and Level 1 for

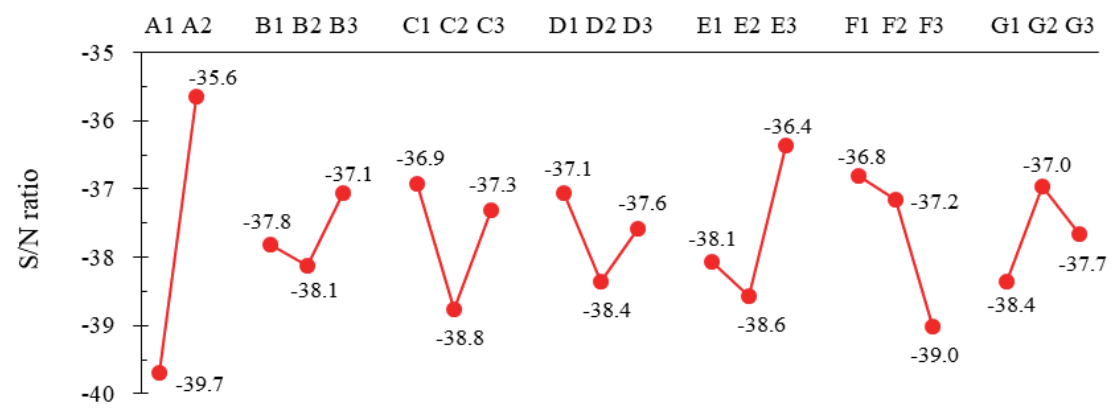

Fig. 4. (Color online) Factor response diagram for case hardness. 
Table 8

ANOVA results of $\mathrm{S} / \mathrm{N}$ ratio for torsional strength.

\begin{tabular}{lcccc}
\hline Factor & $S S$ & DOF & Var. & Contribution (\%) \\
\hline A & 0.39 & 1 & 0.39 & 6.3 \\
B & 1.20 & 2 & 0.60 & 19.2 \\
C & 0.20 & 2 & 0.10 & 3.2 \\
D & 1.32 & 2 & 0.66 & 21.1 \\
E & 1.65 & 2 & 0.82 & 26.4 \\
F & 0.07 & 2 & 0.03 & 1.0 \\
G & 0.24 & 2 & 0.12 & 3.8 \\
Others & 1.19 & 2 & 0.30 & 19.0 \\
Total & 6.25 & 17 & - & 100.0
\end{tabular}

\begin{tabular}{|c|c|c|c|c|c|c|}
\hline \multicolumn{7}{|c|}{ Pooling of errors } \\
\hline Factor & $S S$ & DOF & Var. & $F$ & Confidence (\%) & Significance \\
\hline A & \multicolumn{6}{|c|}{ Pooled } \\
\hline B & 1.20 & 2 & 0.60 & 3.16 & 91.8 & Yes \\
\hline $\mathrm{C}$ & \multicolumn{6}{|c|}{ Pooled } \\
\hline $\mathrm{D}$ & 1.32 & 2 & 0.66 & 3.48 & 93.2 & Yes \\
\hline $\mathrm{E}$ & 1.65 & 2 & 0.82 & 4.35 & 95.9 & Yes \\
\hline $\mathrm{F}$ & \multicolumn{6}{|c|}{ Pooled } \\
\hline G & \multicolumn{6}{|c|}{ Pooled } \\
\hline Others & \multicolumn{6}{|c|}{ Pooled } \\
\hline Error & 2.08 & 11 & 0.19 & & & \\
\hline Total & 6.25 & 17 & \multicolumn{4}{|c|}{${ }^{*}$ At least $90.0 \%$ confidence level } \\
\hline
\end{tabular}

$S S$, sum of squares; DOF, degree of freedom; Var., variance; $F, F$-ratio; $S_{\text {exp }}$, experimental error

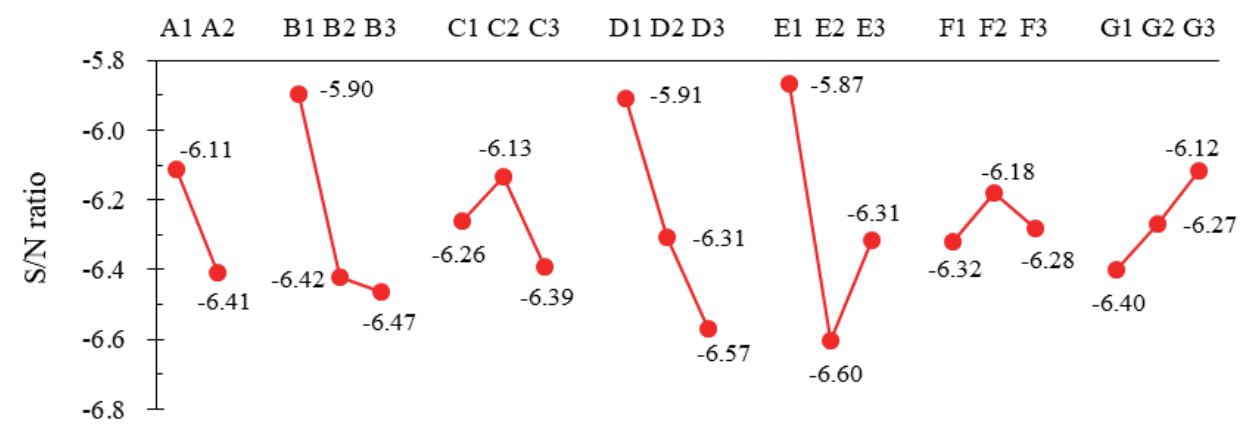

Fig. 5. (Color online) Factor response diagram for torsional strength.

case treatment time (40 min, E1) are evidently optimum, as shown in Fig. 5. The effects of the other four factors are relatively small. The optimum levels are Level 1 for ammonia flow rate $(0.5$ $\mathrm{L} / \mathrm{min}, \mathrm{A} 1)$, Level 2 for feeding weight $(700 \mathrm{~kg} / \mathrm{h}, \mathrm{C} 2)$, Level 2 for carbon potential (1.0\%, F2), and Level 3 for quenchant temperature $\left(90^{\circ} \mathrm{C}, \mathrm{G} 3\right)$.

With the results of the optimum analysis of the quality characteristics of case hardness and torsional strength, the optimum conditions are shown in Table 9. Case treatment primarily provides the needed hard, wear-resistant case for screws and torsional strength (drilling performance) may be increased as well. Ammonia flow rate (A) and carbon potential (F) are significant factors for case hardness. Therefore, the optimum levels are determined as Level 2 
Table 9

Optimum condition table for case treatment.

\begin{tabular}{llccc}
\hline & Factor & $\begin{array}{c}\text { Case } \\
\text { hardness }\end{array}$ & $\begin{array}{c}\text { Torsional } \\
\text { strength }\end{array}$ & Optimum \\
\hline A: & Flow rate of ammonia $\left(\mathrm{NH}_{3}\right)(\mathrm{L} / \mathrm{min})$ & $\mathrm{A} 2^{*}$ & $\mathrm{~A} 1$ & $\mathrm{~A} 2$ \\
$\mathrm{~B}:$ & Flow rate of methanol $\left(\mathrm{CH}_{3} \mathrm{OH}\right)(\mathrm{L} / \mathrm{min})$ & $\mathrm{B} 3$ & $\mathrm{B1}^{*}$ & $\mathrm{~B} 1$ \\
$\mathrm{C}:$ & Feeding weight $(\mathrm{kg} / \mathrm{h})$ & $\mathrm{C} 1$ & $\mathrm{C} 2$ & $\mathrm{C} 2$ \\
$\mathrm{D}:$ Case treating temperature $\left({ }^{\circ} \mathrm{C}\right)$ & $\mathrm{D} 1$ & $\mathrm{D}^{*}$ & $\mathrm{D} 1$ \\
$\mathrm{E}: \quad$ Case treating time $(\min )$ & $\mathrm{E}^{*}$ & $\mathrm{E}^{*}$ & $\mathrm{E} 1$ \\
F: & Carbon potential $(\%)$ & $\mathrm{F}{ }^{*}$ & $\mathrm{~F} 2$ & $\mathrm{~F} 1$ \\
$\mathrm{G}: \quad$ Temperature of quenchant $\left({ }^{\circ} \mathrm{C}\right)$ & $\mathrm{G} 3$ & $\mathrm{G} 2$ \\
\hline
\end{tabular}

*Significant factor

for ammonia flow rate $(0.0 \mathrm{~L} / \mathrm{min}, \mathrm{A} 2)$ and Level 1 for carbon potential $(0.9 \%, \mathrm{~F} 1)$. For torsional strength, methanol flow rate (B) and case treatment temperature (D) are significant. Hence, the optimum levels are determined as Level 1 for methanol flow rate $(1.0 \mathrm{~L} / \mathrm{min}, \mathrm{B} 1)$ and Level 1 for case treatment temperature $\left(860^{\circ} \mathrm{C}, \mathrm{D} 1\right)$. Case treatment time (E) is significant for both case hardness and torsional strength, and Level 1 (40 min, E1) is determined. The other two factors are not significant either for case hardness or torsional strength; thus, Level 2 for feeding weight $(700 \mathrm{~kg} / \mathrm{h}, \mathrm{C} 2)$ and Level 2 for quenchant temperature $\left(85^{\circ} \mathrm{C}, \mathrm{G} 2\right)$ are determined.

\subsection{Confirmation experiments}

To verify the predicted results, the timber screws are fabricated using the optimum levels A2, B1, C2, D1, E1, F1, and G2, as described in Table 9. Figures 6 and 7 show the nontreated, original (using Level 2's in Table 1), and optimal probability distributions for the case/core hardness and torsional strength of AISI 1022 timber screws, respectively.

It is observed that, through case treatment with the original settings, the mean case hardness is increased substantially by about $452 \mathrm{HV}$ as compared with the nontreated results; the mean core hardness is also increased by about $288 \mathrm{HV}$ and the deviations are increased, as shown in Fig. 6. Simultaneously, the mean torsional strength is markedly increased by about $3.7 \mathrm{~N} \cdot \mathrm{m}$, as shown in Fig. 7, which is much greater than the target value of $4.5 \mathrm{~N} \cdot \mathrm{m}$. Compared with the original results, as shown in Fig. 6, the optimum mean case hardness of $673.1 \mathrm{HV}$ is higher than the original mean case hardness of $660.3 \mathrm{HV}$, and the deviation is slightly increased by about $0.8 \%$. The optimum mean core hardness of $440.0 \mathrm{HV}$ is decreased compared with the original mean core hardness of $460.6 \mathrm{HV}$, and the deviation is obviously decreased by about $38.9 \%$. For torsional strength, as shown in Fig. 7, the optimum mean value of $5.30 \mathrm{~N} \cdot \mathrm{m}$ is considerably decreased compared with the original mean value of $6.56 \mathrm{~N} \cdot \mathrm{m}$, and the deviation is obviously decreased by about $31.2 \%$.

The new parameter settings evidently improve the performance measures over their values at the original settings. Therefore, the quality of case-treated AISI 1022 timber screws is effectively improved. 


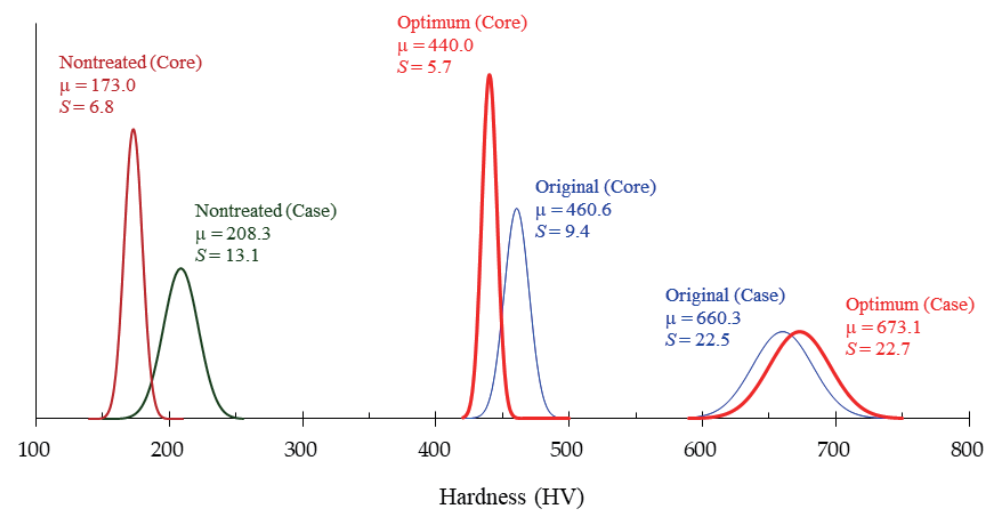

Fig. 6. (Color online) Probability distribution diagram for hardness.

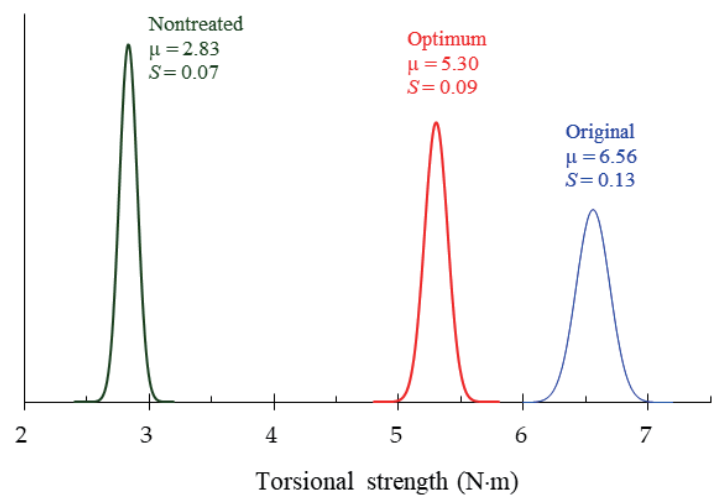

Fig. 7. (Color online) Probability distribution diagram for torsional strength.

\section{Conclusions}

The manufacturing processes of timber screws, which are widely used for construction work, include wire manufacturing, heading and threading, case treatment, and coating. A low-carbon steel wire of AISI 1022 is used to easily fabricate timber screws. The majority of case activity is performed to improve the strength without affecting the soft, tough interior of the screws in drilling operation. In this study, the Taguchi method is used to obtain optimum case treatment conditions to improve the mechanical properties of AISI 1022 timber screws. The quality of case-treated timber screws is affected by various factors, such as case treatment temperature, case treatment time, atmosphere composition, and tempering temperature. The effects of case treatment parameters affect the quality characteristics, such as case/core hardness and torsional strength.

Case treatment primarily provides a needed hard, wear-resistant case of screws and torsional strength (drilling performance) may be increased. It is experimentally revealed that ammonia 
flow rate $(A)$, case treatment time $(\mathrm{E})$, and carbon potential $(\mathrm{F})$ are significant for case hardness, while methanol flow rate (B), case treatment temperature (D), and case treatment time (E) are significant for torsional strength; the determined levels are Level 2 for ammonia flow rate (0.0 L/min, A2), Level 1 for methanol flow rate $(1.0 \mathrm{~L} / \mathrm{min}, \mathrm{B})$, Level 1 for case treatment temperature $\left(860{ }^{\circ} \mathrm{C}, \mathrm{D} 1\right)$, Level 1 for case treatment time (40 min, E1), and Level 1 for carbon potential $(0.9 \%, \mathrm{~F} 1)$. The other two factors are not significant either for case hardness or torsional strength; thus, Level 2 for feeding weight $(700 \mathrm{~kg} / \mathrm{h}, \mathrm{C} 2)$ and Level 2 for quenchant temperature $\left(85^{\circ} \mathrm{C}, \mathrm{G} 2\right)$ are determined. In addition, the optimum mean case hardness is 673.1 $\mathrm{HV}$, the optimum mean core hardness is $440.0 \mathrm{HV}$ and, for torsional strength, the optimum mean value is $5.30 \mathrm{~N} \cdot \mathrm{m}$. The new case treatment parameter settings evidently improve the performance measures over their values at the original settings. The strength of case-treated AISI 1022 timber screws is effectively improved. These results may be used as a reference for fastener manufacturers.

\section{Acknowledgments}

The authors would like to acknowledge the support of TYCOONS Group Enterprise Co., Ltd., Kaohsiung, Taiwan, for providing the materials and apparatus to carry out the case treatment experimental work.

\section{References}

1 C. A. Stickels: Heat Treating (ASM International, Materials Park, 2011).

2 J. I. Goldstein and A. E. Moren: Metall. Trans. A 9 (1978) 11.

3 T. V. Rajan, C. P. Sharma, and A. Sharma: Heat Treatment Principles and Techniques (Prentice-Hall of India Pvt. Ltd., New Delhi, 1994).

4 M. Li: Gear Technology March/April (2016).

5 F. O. Aramide, S. A. Ibitoye, I. O. Oladele, and J. O. Borode: Mater. Res. 12 (2009) 4.

6 Y. Peng, M. Zhang, J. Xiao, J. Dong, and C. Du: J. Mater. Res. 30 (2015) 6.

7 A. S. Ivanov, S. K. Greben'kov, and M. V. Bogdanova: Met. Sci. Heat Treat. 58 (2016) 1.

8 D. H. Herring: Fast. Tech. Int. XXXIV (2011) 3.

9 K.-M. Winter: J. Mater. Eng. Perform. 22 (2013) 7.

10 J. Slycke and T. Ericsson: J. Heat Treat. 2 (1981) 1.

11 L. M. Semenova, Y. S. Bakhracheva, and S. V. Semenov: Met. Sci. Heat Treat. 55 (2013) 1.

12 M. B. Karamiş and R. İpek: Appl. Surf. Sci. 119 (1997) 1.

13 M. L. Fares, A. Talhi, K. Chaoui, and M. Z. Touhami: Surf. Eng. 27 (2011) 8.

14 N. Logothetis: Managing for Total Quality: From Deming to Taguchi and SPC (Prentice Hall International, London, 1992).

15 H.-H. Lee: Taguchi Methods: Principles and Practices of Quality Design (Gau Lih Book, New Taipei City, 2008).

16 C.-C. Yang and X.-Y. Lin: J. Mech. Eng. Autom. 6 (2016) 3. 


\section{About the Authors}

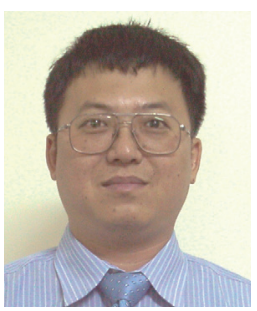

Chih-Cheng Yang received his B.S. degree from Tatung Institute of Technology, Taiwan, in 1985, his M.S. degree from National Cheng Kung University, Taiwan, in 1991, and his Ph.D. degree from Liverpool University, UK, in 1997. From 2000 to 2016, he was an assistant professor at Kao Yuan University, Taiwan. Since 2017, he has been an associate professor at Kao Yuan University. His research interests are in materials, manufacture, and optimum design of engineering.

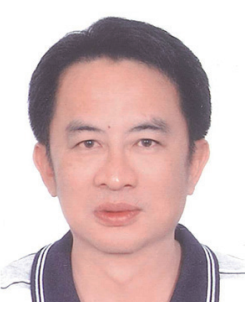

Ching-Yun Yen received his associate degree from National United University, Taiwan, in 1985 and his M.S. from Kao Yuan University, Taiwan, in 2012. Since 1992, He has been working as an assistant manager at TYCOONS Group Enterprise Co., Ltd., Taiwan. His research interests are in materials and heat treatment of fasteners. 